\title{
Stereomic microstructure of Clypeasteroida in thin section based on new material from Pleistocene strata in Taiwan
}

\author{
Yu-Jou Lin ${ }^{1}$, Jiann-Neng Fang ${ }^{2}$, Chien-Chung Chang ${ }^{3}$, Chi-Chieh Cheng ${ }^{3}$, and Jih-Pai Lin ${ }^{1, *}$ \\ ${ }^{I}$ Department of Geosciences, National Taiwan University, Taipei City, Taiwan \\ ${ }^{2}$ Collection Management Department, National Taiwan Museum, Taipei City, Taiwan \\ ${ }^{3}$ Delta Electronics, Inc., Taoyuan City, Taiwan
}

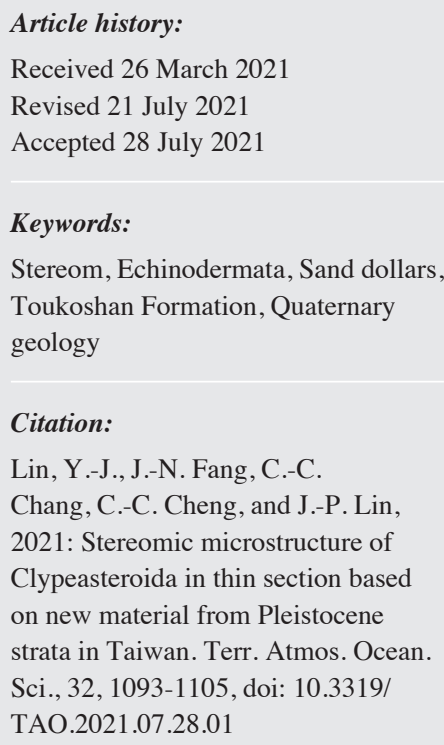

\begin{abstract}
The goal is to document the stereom preservation of a fossil clypeasteroid Scaphechinus mirabilis recovered from the Pleistocene strata in western Taiwan. The adult size of $S$. mirabilis ranges from 4 to $7 \mathrm{~cm}$. Although the living species can be found along the coast in Japan, Korea, and China, only fossil materials have been reported from the Toukoshan Formation in Miaoli, Taiwan. To understand better the fossil stereom preservation of $S$. mirabilis, a total of 971 specimens deposited at the Department of Geosciences, National Taiwan University (NTUG) were examined. An additional 572 specimens were also studied and 65 well-preserved fossil specimens and one modern sample were selected for making thin sections. Among the 86 thin sections, 68 sections were prepared and cut parallel to the bilateral symmetry plane of the echinoid, and the other 18 thin sections were cut through different regions of the test, including apical system, petaloid, and interambulacral areas. Types of stereom and the associated tissues can be determined by calculating the pore size and minimum thickness of trabeculae. Results show that plate boundaries, growth lines, and stereom are clear and identifiable under a polarized microscope. Dominant types of stereom include labyrinthic, rectilinear and galleried stereom.
\end{abstract}

\section{INTRODUCTION}

Stereomic microstructure known as stereom is the fundamental building block of echinoderm ossicles, and they are key features to interpret the function(s) of echinoderm ossicles that originated during the Cambrian (Clausen and Smith 2005). Stereom consists of a three-dimensional mesh of trabeculae filled with interconnecting pores. Trabeculae are comprised of high-magnesium calcite, and behave as a single crystal in each ossicle (Gorzelak et al. 2016; Gorzelak 2018). At least nine types of stereom have been reported from both living and fossil echinoids (Fig. 1). Stereom studies are crucial to understand the phylogeny, growth, and soft tissue of the Echinoidea (Pearse and Pearse 1975; Seilacher 1979; Smith 1980, 1984, 1989, 1991; Ebert 2013; Grun and Nebelsick 2018a, b, c).

Fossil echinoids from Taiwan have been studied for decades, and many impressive collections are housed in both

\footnotetext{
* Corresponding author

E-mail: alexjplin@ntu.edu.tw
}

public and private museums in Taiwan. According to Lin and Chou (1978, p. 13), the earliest known report of Taiwanese fossil echinoderms was on fossil echinoids by Henry Brougham Guppy (1854 - 1926) in 1881, but the reported genus, Scutella, was probably misidentified (Wang 1982a). In 1885, G. A. Lebour reported two species Echinodiscus bioculatus Agassiz and E. bisperforatus Leske from Taiwan; however, those names were not considered as valid names by later authors (e.g., Yoshiwara 1901, p. 62; Hayasaka and Morishita 1947 a, p. 39). During the early $20^{\text {th }}$ Century, Taiwanese echinoderms were mainly studied by Japanese scholars. Yoshiwara (1903) reported three fossil echinoids from Taiwan: Astriclypeus integer, Echinodiscus formosus, and Schizaster sp. Deguchi (1912) listed 11 localities of fossil echinoids from Taiwan. After the end of the Second World War, echinoderm studies were resumed and led by the famous paleontologist Ichirô Hayasaka (1891 - 1977) (Hayasaka and Morishita 1947a, b; Hayasaka 1948a, b). Nisiyama $(1966,1968)$ reviewed and summarized previous 
(a)

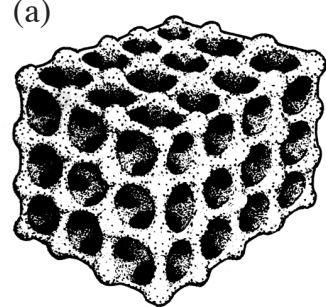

(d)

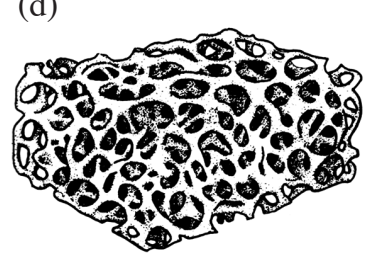

(g)

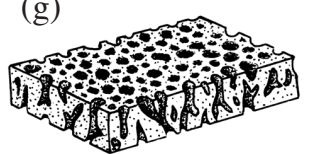

(b)

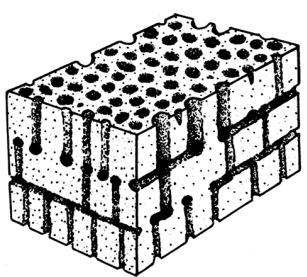

(e)

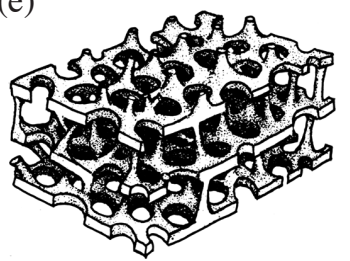

(h)

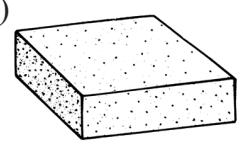

(c)

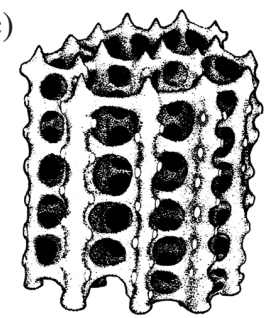

(f)

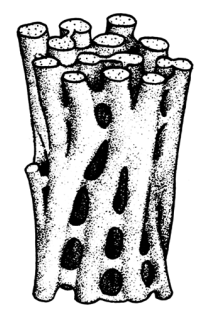

(i)

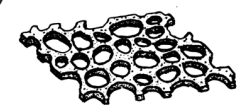

Fig. 1. Types of stereomic microstructure (stereom) (modified from Smith 1980). (a) Rectilinear; (b) microperforate; (c) galleried; (d) labyrinthic; (e) laminar; (f) fascicular; (g) perforate; (h) imperforate; (i) retiform.

studies of echinoid faunas from Japan and adjacent regions, including Taiwan. Lin and Chou (1978, p. 441 - 444) listed 11 fossil echinoid families reported from Taiwan. New findings were discovered during the field mapping project in the 1980s. This material became the core research collection of the Master's study of Chia-Ching Wang at the National Taiwan University. Wang's studies (e.g., Wang 1982a, b, 1984, 1986; Wang et al. 1984) marked an important milestone for Taiwan fossil echinoid research. By reviewing Wang's collections housed at the Department of Geosciences, National Taiwan University, new specimens are collected by re-visiting classic fossil localities. This study is a part series of reviewing and restudying Taiwanese clypeasteroids (e.g., Lee et al. 2019). The goal here is to study the stereom preservation based on Scaphechinus mirabilis, which is one of the most common fossil clypeasteroids recovered from the Pleistocene strata in western Taiwan (Morishita 1967; Wang et al. 1984).

\section{REGIONAL GEOLOGY}

Fossils are recovered from the Toukoshan Formation (Pleistocene) in Miaoli (Fig. 2), and the unit crops out in Hsinchu, Miaoli, and Taichung in western Taiwan. The unit can be divided into two members: Hsiangshan sandstone and Huoyenshan conglomerate. Fossil sand dollars commonly occur in the Hsianshan member. Based on magnetostratigraphy, the lower part of the unit belongs to the Jaramillo subchron (1.07 - $0.99 \mathrm{Ma}$ ) within the Matuyama Chron (Chen 2016). Chen et al. (1977) interpreted the lower boundary between Toukoshan Formation and the underlying Cholan Formation to be 1.3 Ma in age.

\section{METHODOLOGY}

The basic body plans of sea urchins or echinoids can be categorized into two groups: regular and irregular echinoids (Durham et al. 1966; Smith 1984; Mooi 1989). Studied materials are fossil specimens of Scaphechinus mirabilis, which is an irregular urchin with a bilateral symmetry. Standard terminology is explained in Fig. 3. In order to examine the marginal plates and stereom types under polarized light microscopes (PLM), the quality of thin sections is crucial.

Raw samples were cleaned, and the well-preserved fragments were selected to be trimmed down to $2 \mathrm{~cm}^{2}$. Samples were then polished with 320-, 400-, 600-, 800-, and 1000-grit sandpapers. Samples were affixed to a glass slide with epoxy and dried in the oven for 2 hours. When the thin sections were polished to $30 \mu \mathrm{m}$ in thickness, they were ready for PLM study (Fig. 4). Under PLM, echinoid ossicle could be recognized in both plain and polarized light (Figs. 4a, b, respectively). In order to enhance the contrast, an accessory plate (gypsum plate in this case) was inserted (Fig. 4c). Serial sections along the axial petaloid (Fig. 5a) revealed different internal features (Figs. $5 \mathrm{c}-\mathrm{e}$ ). When sectioned across the interporiferous zone (Figs. 5b, c), there were no supporting structures. Pillars and other supporting structures were visible in thin sections made outside of this zone (Figs. 5d, e).

For comparison sections and fragments of modern 


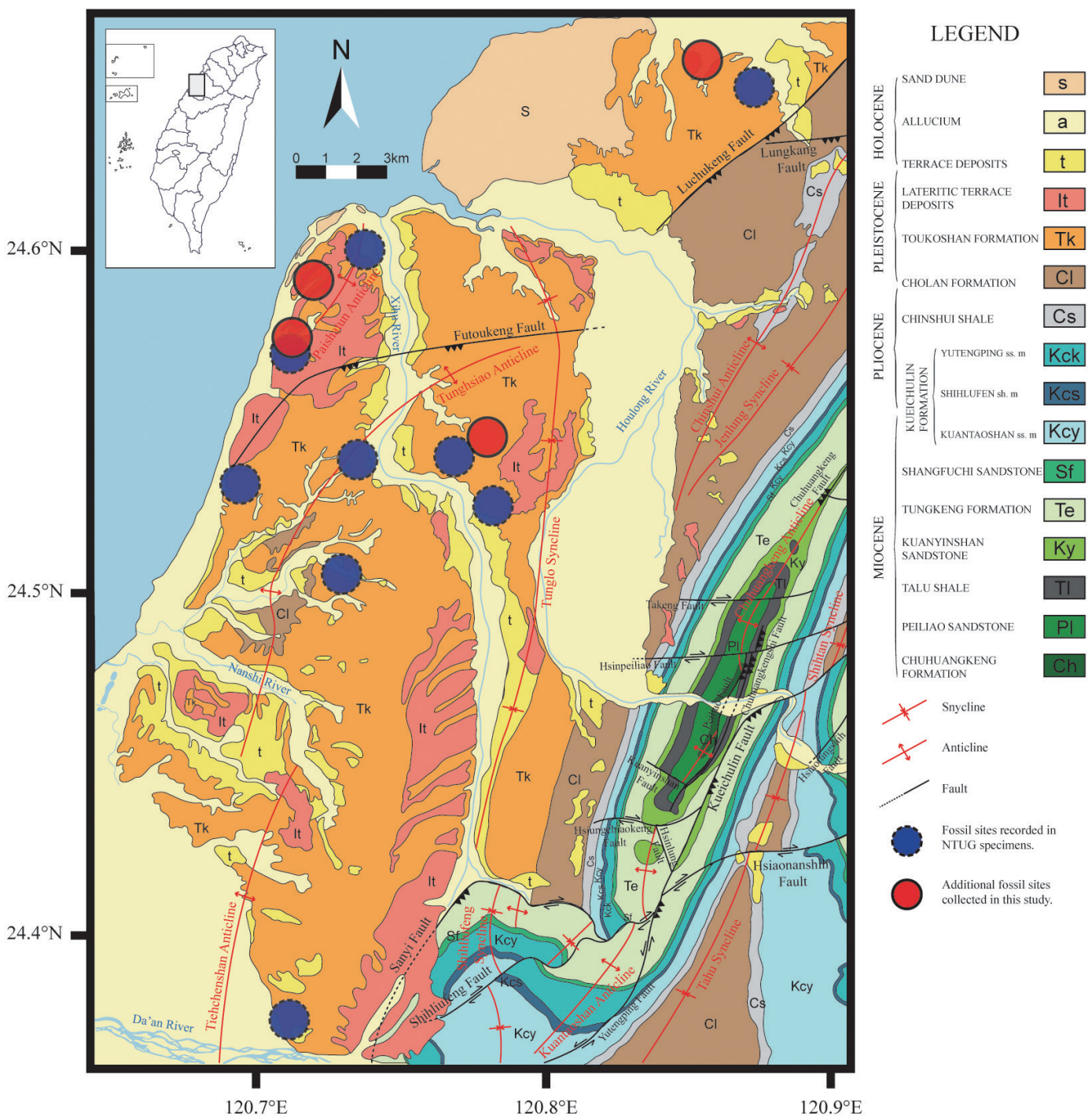

Fig. 2. Geologic map of studied area redraw from 1:50000 geologic map sheets (Paishatun, Miaoli, Tachia, and Tungshih) published by the Central Geological Survey.

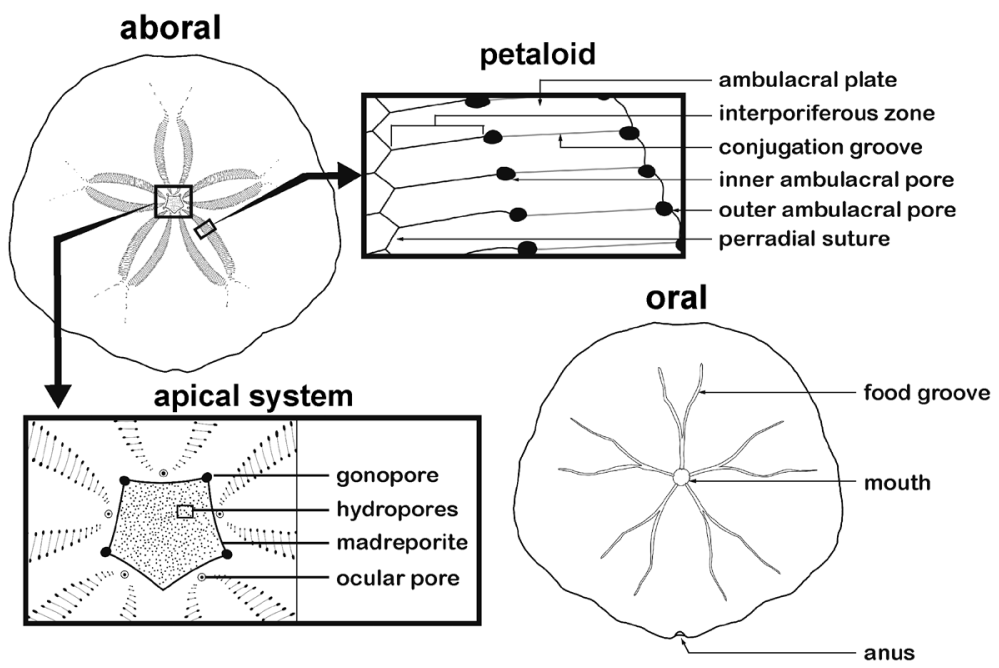

Fig. 3. Morphology of Scaphechinus mirabilis (modified from Lin 2021). 


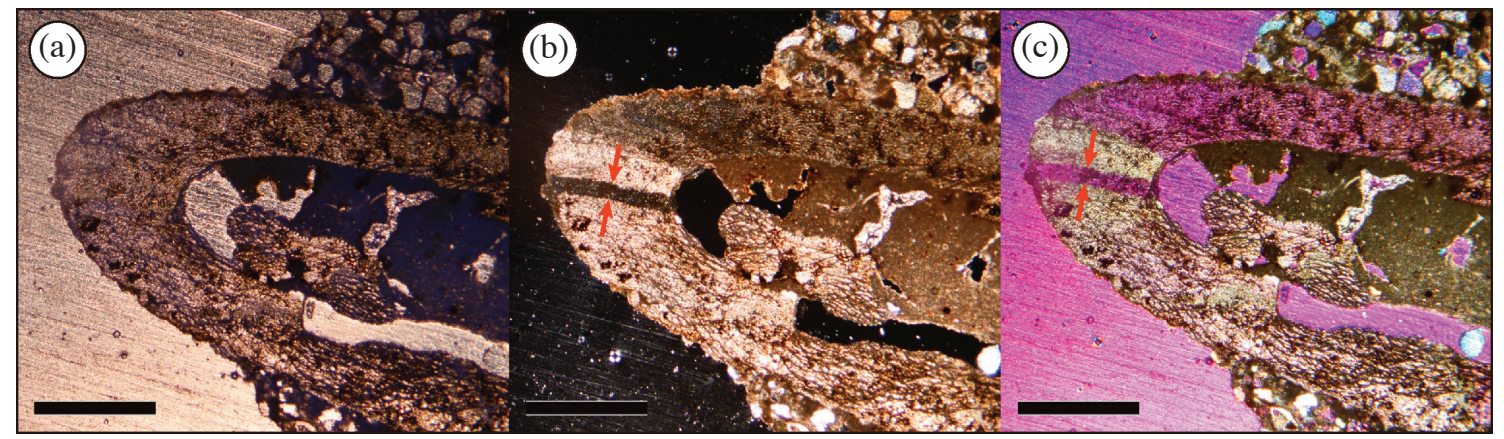

Fig. 4. Longitudinal section (NTUG300-FU01033) of S. mirabilis under polarized light. Scale bar = 1 mm. (a) Open nicol; (b) crossed nicols; (c) crossed nicols with a gypsum plate. Plate boundaries are marked by arrows.

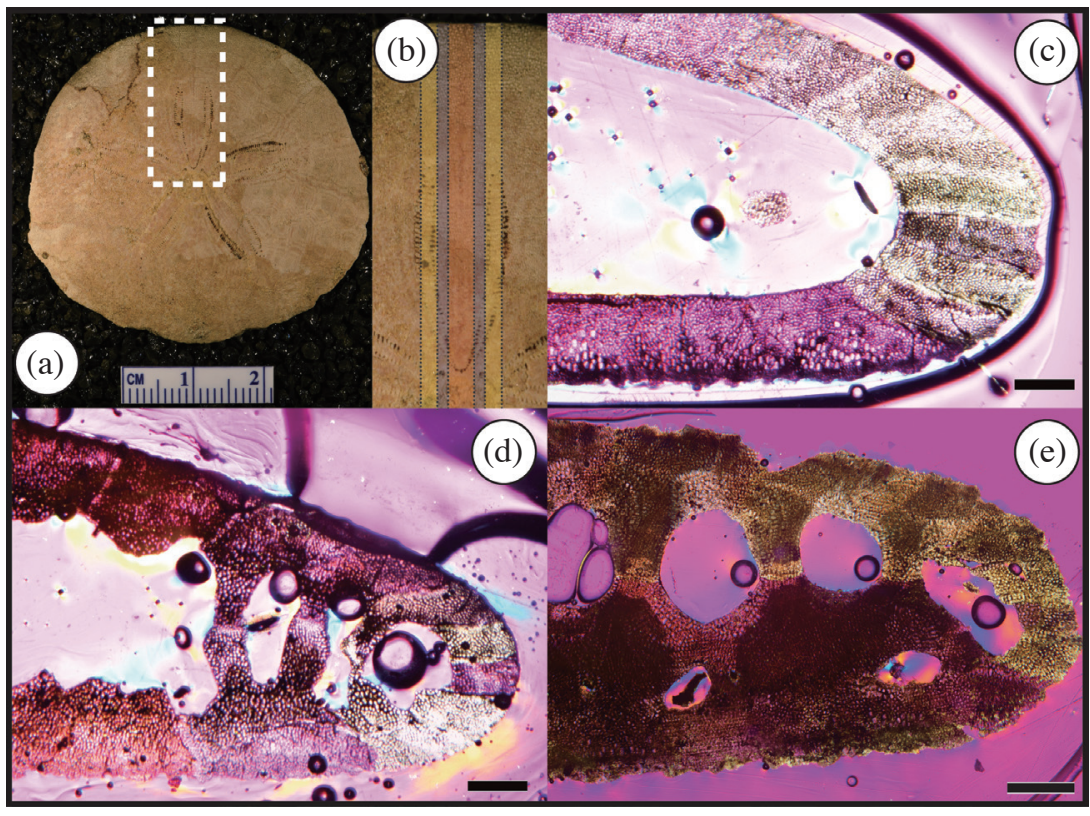

Fig. 5. Studied areas for making thin sections in different orientations. Scale bars: $0.5 \mathrm{~cm}$ (b) - (d). (a) A complete sample (NTUG300-FU01057) of S. mirabilis and the studied area (indicated by dash lines) shown in (b); (b) orientation of thin sections (NTUG300-FU01057); orange area is the target region (the interporiferous zone); yellow areas are the outer parts of petaloids; gray areas are between the two areas mentioned above; (c) sectional profile (NTUG300-FU01057) of marginal plates without pillars or supporting structures, cutting through the orange area shown in (b); (d) sectional profile (NTUG300-FU01054) of marginal plates with pillars, cutting through the gray area shown in (b); (e) sectional profile (NTUG300FU01035) of marginal plates with dense supporting structures, cutting through the yellow area shown in (b). 
specimens of S. mirabilis from Japan were obtained. In particular, detailed morphologic features of tubercles were examined further under the scanning electron microscope (SEM) and reported here (e.g., Figs. 6a, b, 7a, b, 8a, 9a, b, $10 \mathrm{a}, \mathrm{c})$. Well-preserved specimens were also examined under the microcomputed tomography $(\mu \mathrm{CT})$ via DELab $\mu \mathrm{CT}$ 100X made by Delta Electronics, Inc. (Fig. 11).

Stereom was studied by measuring the average minimum diameter of trabecular thickness and the average maximum diameter of interconnecting pores. For assessing the stereom coarseness Smith (1980) divided the interconnecting pores into three levels according to their size: coarse (> $25 \mu \mathrm{m})$, medium $(10-25 \mu \mathrm{m})$, and fine $(<10 \mu \mathrm{m})$. By calculating the coarseness and trabecular thickness, we calculated the stereom porosity based on the following equation:

$\phi=\bar{A} / \bar{t}$

in which, porosity $(\phi)$ is the average maximum diameter of interconnecting pores $(\bar{A})$ divided by the average minimum diameter of trabecular thickness $(\bar{t})$. Four degrees of stereom porosity defined in Smith (1980) were adopted here: compact $(\bar{A} / \bar{t}<1)$, dense $(2>\bar{A} / \bar{t}>1)$, open $(4>\bar{A} / \bar{t}>$ 2), and sparse $(\bar{A} / \bar{t}>4)$ (Fig. 12).

\section{RESULTS}

\subsection{Tubercle Stereom}

Under SEM, tubercles of modern $S$. mirabilis can be subdivided into six regions (Figs. 6a, b). The center is known as the central ligament pit (I in Fig. 6b), in where the central ligament attaches to the spine. The pit is surrounded by bulbous area called mamelon (II in Fig. 6b) that is composed of imperforate stereom (Fig. 1h). Mamelon is connected to petal-like features known as crenulated platform (III in Fig. 6b) with imperforate stereom. The outer region on the raised platform below the imperforate stereom is the boss (IV in Fig. 6b) that is made out of labyrinthic stereom (Fig. 1d). There is a sharp boundary between the raised region and the adjacent concave area known as areole ( $\mathrm{V}$ in Fig. 6b) with much larger interconnecting pores. Lastly, sometimes there is a zone with small interconnecting pores known as the scrobicular zone (VI in Fig. 6b), covering the outermost region of a tubercle. Fossil specimens are relatively less well-preserved, but the boss and areole regions can be distinguished easily, depending on the depth of the section (Figs. 6c-e).

Measurements are based on the labyrinthic stereom in both boss and areole regions. The coarseness of boss is 10.9 $\mu \mathrm{m}$ and the trabecular thickness is $12.3 \mu \mathrm{m}$ on average. In the areole, the stereom coarseness is $18.6 \mu \mathrm{m}$ and the trabecular thickness is $10.2 \mu \mathrm{m}$ on average (Table 1). In general, the areole is where muscle fibres are attached; thus, the interconnecting pores are approximately $7.7 \mu \mathrm{m}$ larger than that in the boss region, whereas the trabecular thicknesses are $2.1 \mu \mathrm{m}$ smaller than that in the boss region (Figs. 12a, b).

\subsection{Petaloid Stereom}

Petaloids are characterized by the distinct pore system known as pore-pairs. Under SEM, it is evident that individual plate boundaries run through pores (Figs. 7a, b). Under polarized light, plates are elongated, parallel to the pore-pairs, and continuous to the perradial suture lines (Figs. 7c, d). Boundaries between plates do not meet symmetrically; instead, there are noticeable translocations among adjacent plates.

Petaloids are dominated by rectilinear stereom. Mean coarseness is $14.6 \mu \mathrm{m}$ based on 55 measurements, and trabecular thickness is $12.2 \mu \mathrm{m}$ on average based on 78 measurements. Calculated stereom porosity is 1.19 , belonging to the dense grade.

\subsection{Oral-Plate Stereom}

Oral plates grow from the center and radiate outward with galleried stereom (Figs. 8a - c). There are solid spikes (Seilacher 1979) near the plate margins, forming trabecular interlocking-type plate boundary of Grun and Nebelsick $(2018 b, c)$. Spikes with imperforate stereom are $20.3 \mu \mathrm{m}$ on average thickness based on 98 measurements. In the galleried stereom, the coarseness is $19.2 \mu \mathrm{m}$ on average based on 242 measurements; the trabecular thickness is $12.2 \mu \mathrm{m}$ on average based on 261 measurements. The calculated porosity is 1.57 , belonging to the dense grade (Fig. 12c).

\subsection{Lantern Stereom}

Due to the relatively small opening for the peristome, the lantern is typically preserved within the test cavity of sand dollars in Taiwan. Under SEM, elements of lantern consist of branching trabeculae (Figs. 9a, b); thus, it is diagnostic for fascicular stereom (Fig. 1f). In thin sections (Fig. 9c), trabecular thickness varies; thus, meaningful measurements are not feasible. All the stereom measurements and porosity calculations are summarized in Table 1 .

\section{DISCUSSION}

\subsection{Comparisons of Modern and Fossil S. Mirabilis}

By comparing SEM images (Figs. 6a, b) and thin sections (Fig. 10) of both modern and fossil S. mirabilis, it is clear that the modern sample contains more surficial features, such as detailed morphologies of tubercles (Figs. 6a, b, 10a, c). Although the fossil specimens typically have more surface abrasion, internal stereom have a little compaction and the interconnecting pores retain original geometry (Figs. 10b, d). 


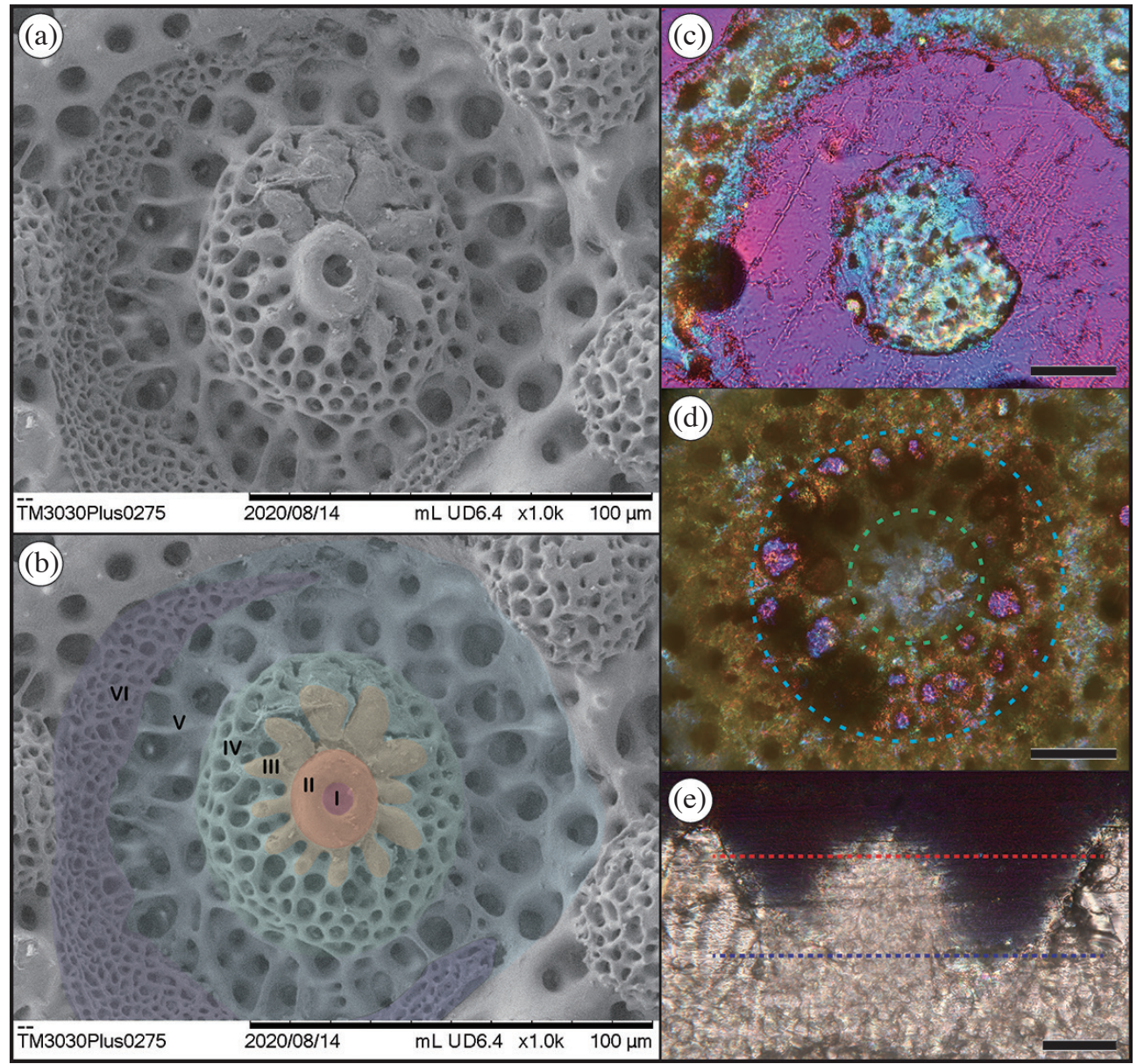

Fig. 6. Tubercle stereom under SEM (a) (b) and under polarized light microscope (PLM) (c) - (e). Scale bars: $100 \mu \mathrm{m}$ (a) (b); $50 \mu \mathrm{m}$ (c) - (e). (a) An original tubercle under SEM; (b) a tubercle subdivided into 6 regions that have different stereom types (I: central ligament pit, II: mamelon, III: crenulate platform, IV: boss, V: areole, VI: scrobicular zone.); (c) close-up of a tubercle highlighting mamelon and boss stereom (NTUG300FU01067), cutting approximately through the red line illustrated in (e); (d) close-up of a tubercle highlighting boss (green dotted line region) and areole (between blue and green dotted line region) stereoms (NTUG300-FU01067), cut approximately through the blue line illustrated in (e); (e) longitudinal section (NTUG300-FU01086) of one tubercle with red and blue section surfaces presented above. 


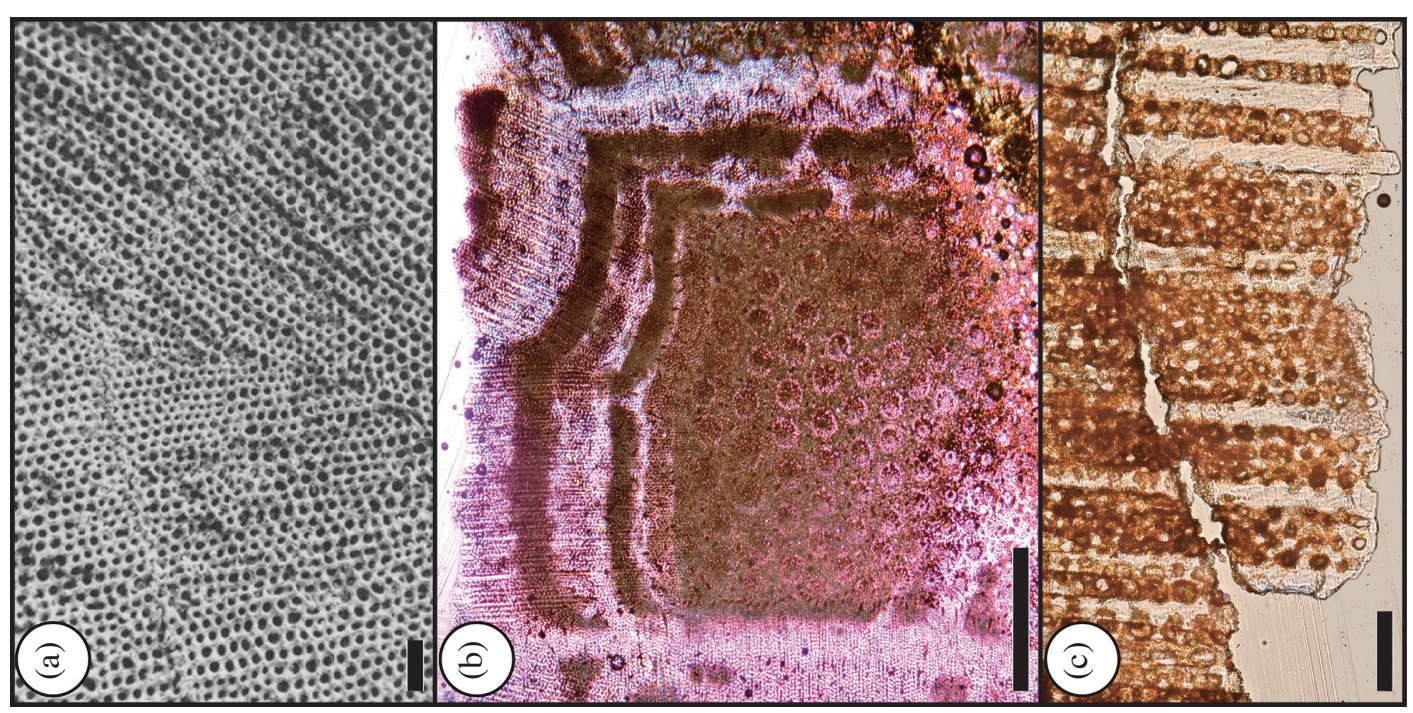

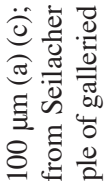

苛 焉

बु

on $\sum_{1}: \overrightarrow{\tilde{*}}$

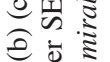

$\sum$ 至

a

ह

范

ฮิ

$\sum$ 可

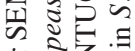

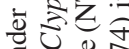

获

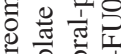

क 월

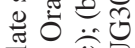

원?

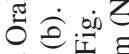

क
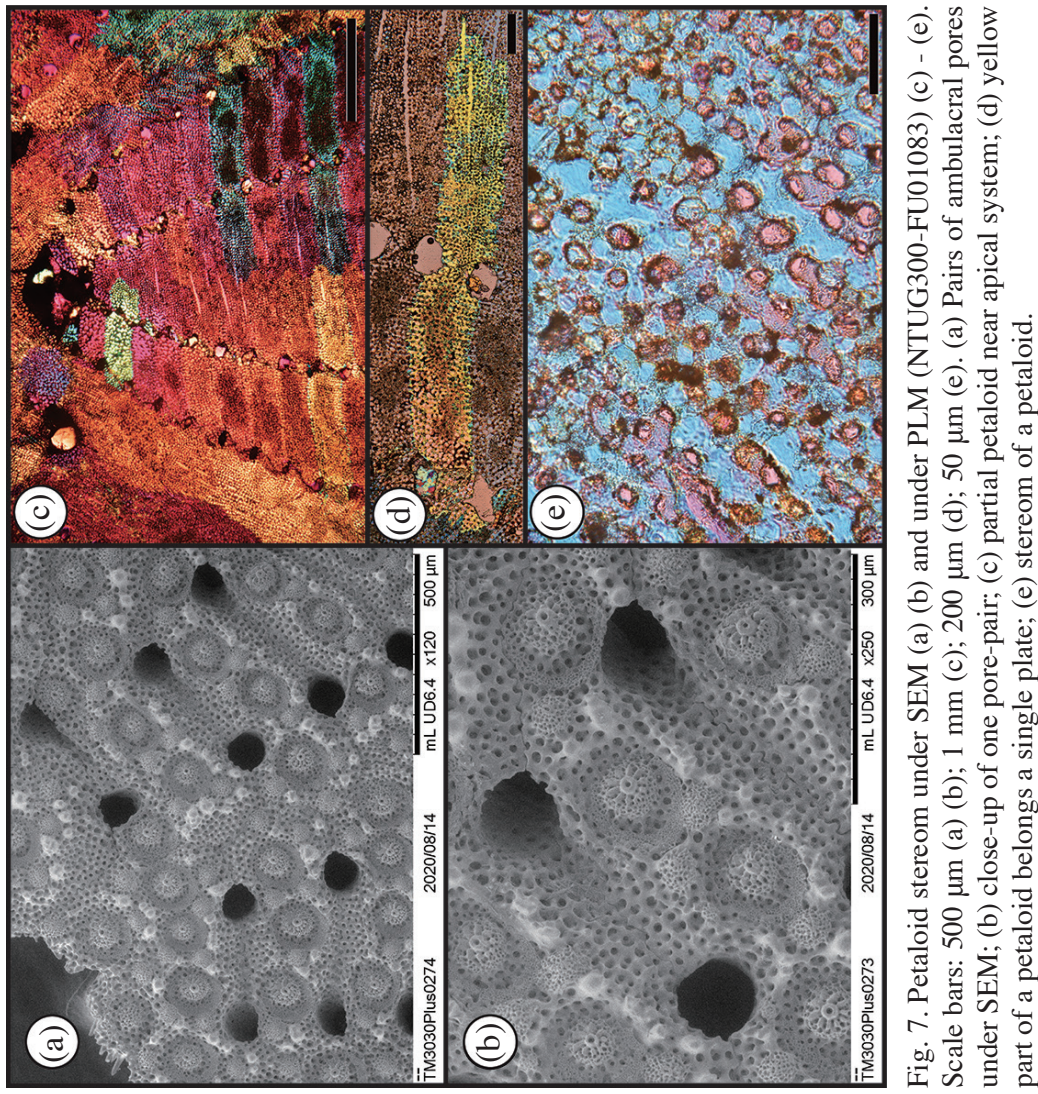


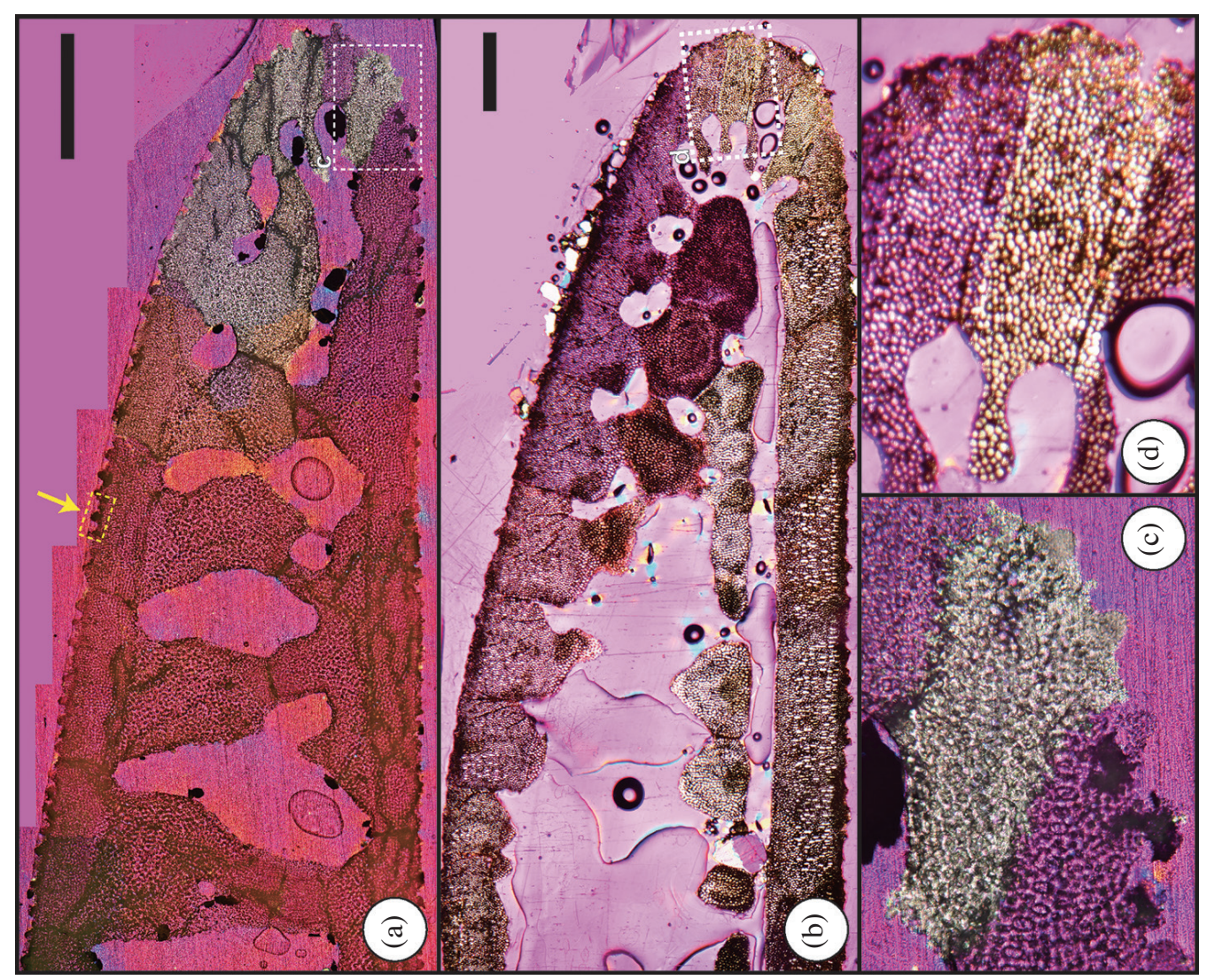

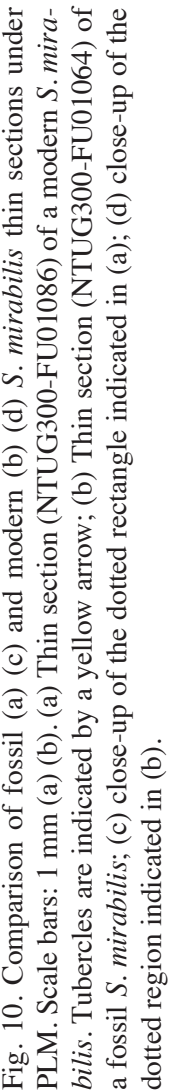

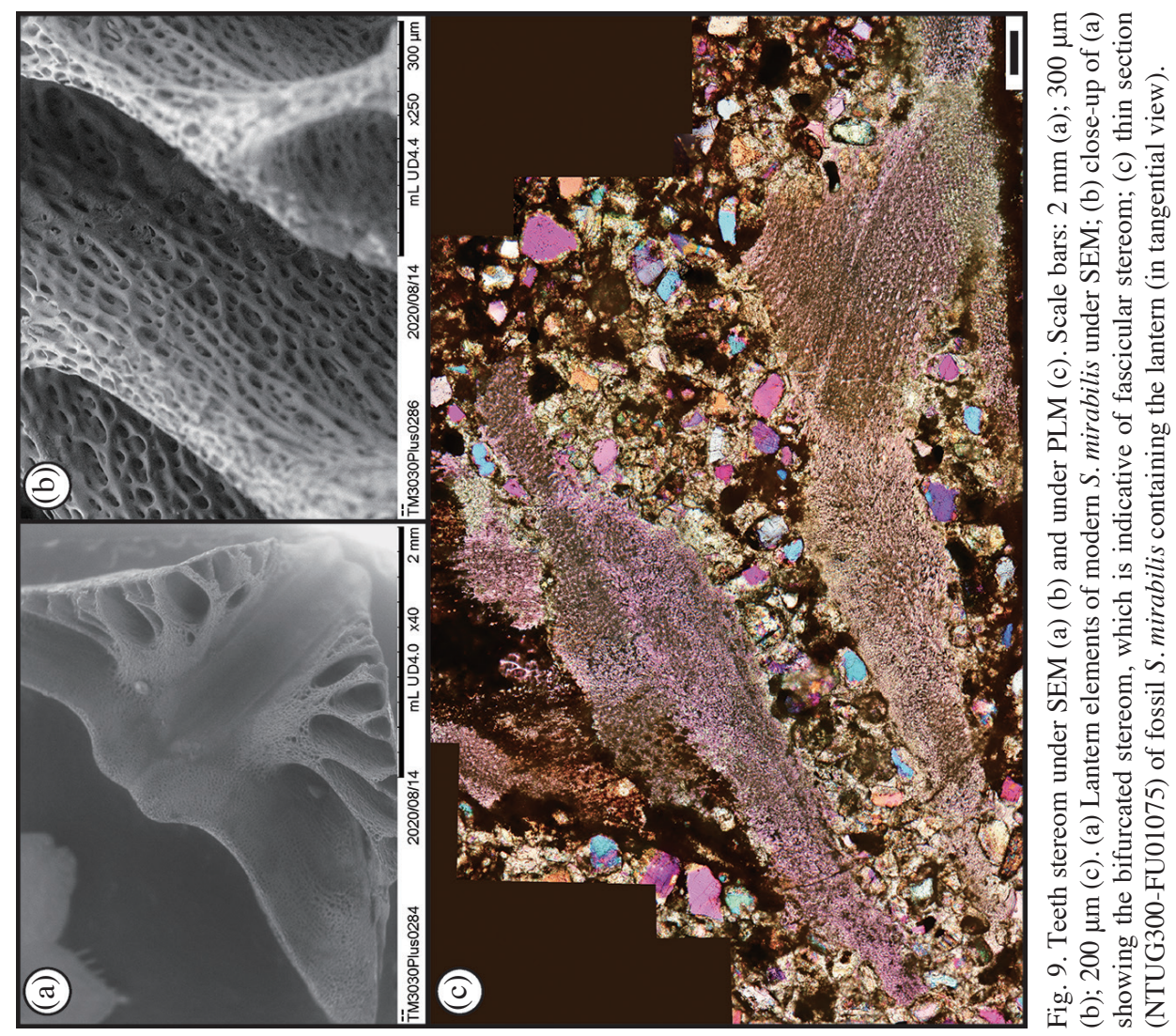



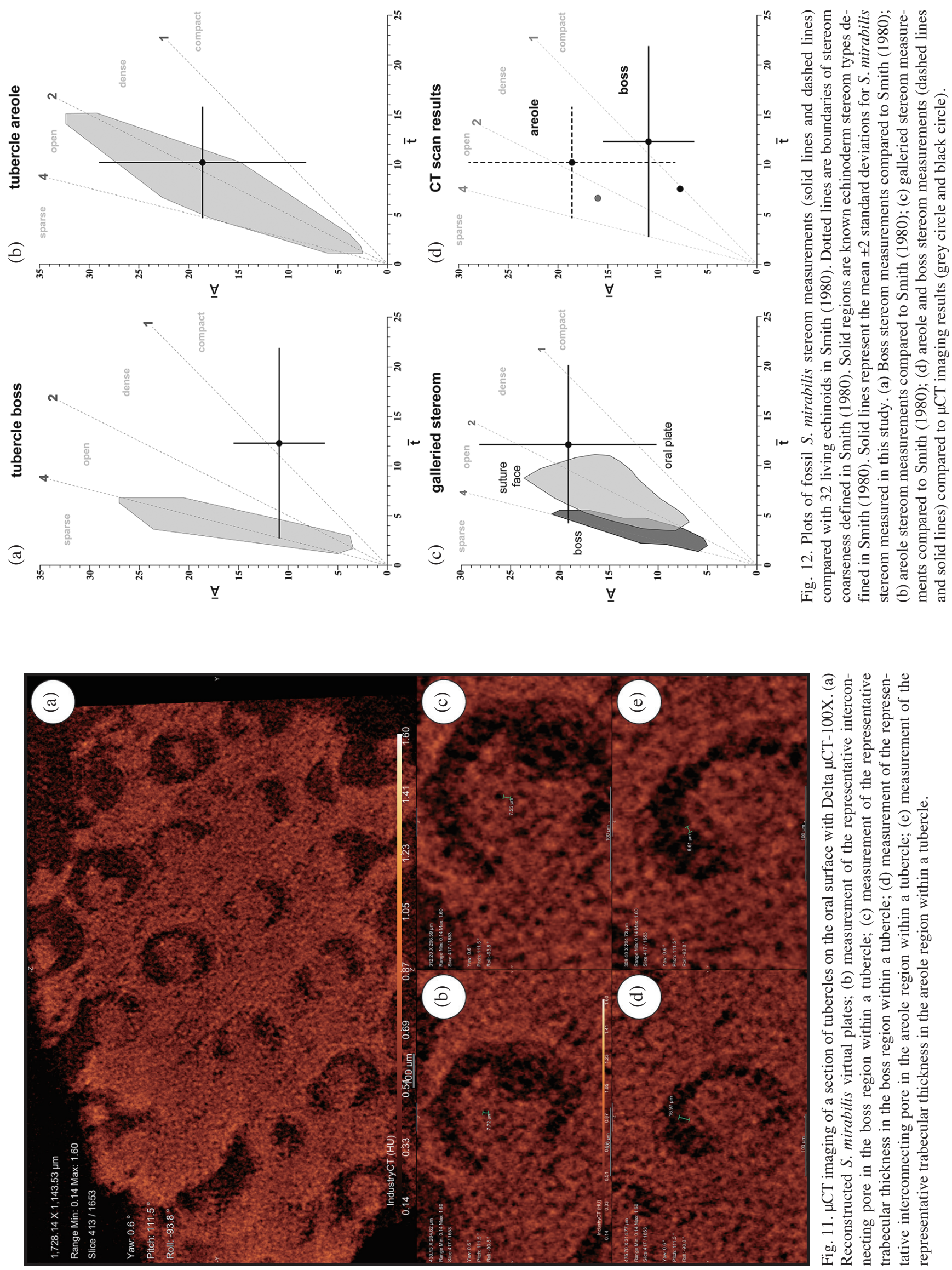
Table 1. Summary of stereom measurements based on fossil S. mirabilis from Taiwan.

\begin{tabular}{c|cccc}
\hline & Boss & Areole & Petaloid & Oral plate \\
\hline Stereom type & Labyrinthic & Labyrinthic & Rectilinear & Galleried \\
Mean pore diameter & $10.9 \mu \mathrm{m}(\mathrm{n}=52)$ & $18.6 \mu \mathrm{m}(\mathrm{n}=130)$ & $14.6 \mu \mathrm{m}(\mathrm{n}=55)$ & $19.2 \mu \mathrm{m}(\mathrm{n}=242)$ \\
Trabecular thickness & $12.3 \mu \mathrm{m}(\mathrm{n}=78)$ & $10.2 \mu \mathrm{m}(\mathrm{n}=159)$ & $12.2 \mu \mathrm{m}(\mathrm{n}=78)$ & $12.2 \mu \mathrm{m}(\mathrm{n}=261)$ \\
Porosity & 0.9 & 1.8 & 1.2 & 1.6 \\
& compact & dense & dense & dense \\
\hline
\end{tabular}

Interconnecting pores are where soft tissues attached; thus, there are commonly stained by dark materials in fossil specimens. In contrast, the trabeculae are translucent and retain their optical properties. In particular, individual plate still behaves as single high-Mg calcite (Towe 1967; Weber 1969; Smith 1989; Davies and John 2019) and exhibits uniaxial extinction under PLM.

\section{$5.2 \mu \mathrm{CT}$ Imaging}

$\mu \mathrm{CT}$ imaging is a non-destructive technique to visualize fossil urchins based on X-ray (Grun and Nebelsick 2018a). With the $\mu \mathrm{CT}-100 \mathrm{X}$, the main advantage is that virtual thin-slices in any angles are possible based on the computed three-dimensional reconstruction, allowing a detailed comparison with images of our thin sections. A well-preserved fragment was tested with this method, and our initial findings include the following. First, the image is monotone and only the dense calcite materials can be preserved, and the interconnecting pores are left empty. This makes the distinctions between the trabeculae and interconnecting pore space much easier. Second, due to the high imaging resolution $(\sim 1 \mu \mathrm{m})$ the measurements are more precise than those based on optical microscope images. For example, the boss trabeculae are $7.55 \mu \mathrm{m}$ in minimum thickness, the interconnecting pore is $7.72 \mu \mathrm{m}$ in size, areole trabeculae are 6.61 $\mu \mathrm{m}$ in minimum thickness, and the interconnecting pore is $16.97 \mu \mathrm{m}$ (Figs. 11, 12d) in size.

\section{CONCLUSION}

(1) Because fossil specimens are so well-preserved that trabeculae still behave as a single crystal for each ossicle. Under PLM, plate boundaries can be identified clearly and several types of microstructure, including rectilinear, galleried, and labyrinthic stereoms, can be measured (Table 1) and documented.

(2) Boss region consists of labyrinthic stereom. The mean pore diameter of the boss region within a tubercle is $10.9 \mu \mathrm{m}$ based on 52 measurements, and the average trabecular thickness is $12.3 \mu \mathrm{m}$ based on 78 measurements. The porosity of tubercle boss is compact $(0.9$; Table 1). Observed results of trabecular thickness based on thin sections seem to be larger than those reported in Smith (1980).

(3) Areole region is comprised of labyrinthic stereom. The mean pore diameter of the areole region within a tubercle is $18.6 \mu \mathrm{m}$ based on 130 measurements, and the average trabecular thickness is $10.2 \mu \mathrm{m}$ based on 159 measurements. Porosity of tubercle areole is dense (1.8; Table 1). Areole is the place where spine muscles are attached, so both the mean pore diameter and porosity are larger than that of boss.

(4) Petaloid is dominated by rectilinear stereom. The mean pore diameter of petaloid is $14.6 \mu \mathrm{m}$ based on 55 measurements, and the average trabecular thickness is 12.2 $\mu \mathrm{m}$ based on 78 measurements. The porosity of petaloid stereom is dense (1.2; Table 1$)$.

(5) Oral plate is dominated by galleried stereom. The mean pore diameter is $19.2 \mu \mathrm{m}$ based on 242 measurements, and the average trabecular thickness is $12.2 \mu \mathrm{m}$ based on 261 measurements. The porosity of galleried stereom in oral plates is dense (1.6; Table 1).

(6) On the margins of oral plates, some spike-like trabeculae, penetrating into adjacent plates are present. The average trabecular thickness of these spikes is $20.3 \mu \mathrm{m}$ based on 98 measurements.

(7) Measurements based virtual reconstructions of $\mu \mathrm{CT}$ $100 \mathrm{X}$ images fit within the ranges of our results derived from thin sections.

Acknowledgements Special thanks to Chia-Hsiang Wang for donating some studied fossil specimens; Wei-Chia Chu for accessing the SEM instrument; Satoshi Takeda for donating living specimens for comparison; Min-Yuan Tseng for arranging the visit to use the $\mu \mathrm{CT}-100 \mathrm{X}$ machine in the Delta factory. This study was funded by Taiwan Ministry of Science and Technology (MOST 108-2116-M-002-014; MOST 109-2116-M-002-020; and MOST 110-2116-M002-016 to JPL).

\section{REFERENCES}

Chen, P.-H., T.-C. Huang, C.-Y. Huang, M.-J. Jiang, S.-L. Lo, and C.-L. Kuo, 1977: Paleomagnetic and coccolith stratigraphy of Plio-Pleistocene shallow marine 
sediments, Chuhuangkeng, Miaoli. Petrol. Geol. Taiwan, 14, 219-239.

Chen, W.-S., 2016: Introduction to Geology of Taiwan, Geological Society of Taiwan, Taipei, Taiwan, 204 pp. (in Chinese)

Clausen, S. and A. B. Smith, 2005: Palaeoanatomy and biological affinities of a Cambrian deuterostome (Stylophora). Nature, 438, 351-354, doi: 10.1038/nature04109. [Link]

Davies, A. J. and C. M. John, 2019: The clumped $\left({ }^{13} \mathrm{C}-\right.$ ${ }^{18} \mathrm{O}$ ) isotope composition of echinoid calcite: Further evidence for "vital effects" in the clumped isotope proxy. Geochim. Cosmochim. Acta, 245, 172-189, doi: 10.1016/j.gca.2018.07.038. [Link]

Deguchi, Y., 1912: Catalogue of fossils from Formosa. The Journal of the Geological Society of Japan, 19, 419428. (in Japanese)

Durham, J. W., H. B. Fell, A. G. Fischer, P. M. Kier, R. V. Melville, D. L. Pawson, and C. D. Wagner, 1966: Echinoids. In: Moore, R. C. (Ed.), Treatise on Invertebrate Paleontology, Part U: Echinodermata 3, Vol. 1 $\& 2$, The Geological Society of America, Inc. and The University of Kansas Press, Boulder and Lawrence, U211-U640.

Ebert, T. A., 2013: Growth and survival of postsettlement sea urchins. In: Lawrence, J. M. (Ed.), Sea Urchins: Biology and Ecology, Developments in Aquaculture and Fisheries Science, Volume 38, Elsevier, 83-117, doi: 10.1016/B978-0-12-396491-5.00007-1. [Link]

Gorzelak, P., 2018: Microstructural evidence for stalk autotomy in Holocrinus - The oldest stem-group isocrinid. Palaeogeogr. Palaeoclimatol. Palaeoecol., 506, 202207, doi: 10.1016/j.palaeo.2018.06.036. [Link]

Gorzelak, P., T. Krzykawski, and J. Stolarski, 2016: Diagenesis of echinoderm skeletons: Constraints on paleoseawater $\mathrm{Mg} / \mathrm{Ca}$ reconstructions. Global Planet. Change, 144, 142-157, doi: 10.1016/j.gloplacha.2016.07.010. [Link]

Grun, T. B. and J. H. Nebelsick, 2018a: Structural design of the echinoid's trabecular system. PLOS ONE, 13, e0204432, doi: 10.1371/journal.pone.0204432. [Link]

Grun, T. B. and J. H. Nebelsick, 2018b: Structural design of the minute clypeasteroid echinoid Echinocyamus pusillus. R. Soc. Open Sci., 5, 171323, doi: 10.1098/ rsos.171323. [Link]

Grun, T. B. and J. H. Nebelsick, 2018c: Technical biology of the clypeasteroid echinoid Echinocyamus pusillus: A review. Contemp. Trends. Geosci., 7, 247-254. Available at https://www.kgs.wnoz.us.edu.pl/ctg/ctgarchive/ctg-2018-7-2/.

Hayasaka, I., 1948a: Notes on some fossil echinoids of Taiwan, III. Acta Geol. Taiwan., 1, 111-128.

Hayasaka, I., 1948b: Notes on some fossil echinoids of Taiwan, IV . Acta Geol. Taiwan., 2, 85-124.
Hayasaka, I. and A. Morishita, 1947a: Fossil species of Clypeaster from Taiwan. Acta Geol. Taiwan., 1, 39-52.

Hayasaka, I. and A. Morishita, 1947b: Notes on some fossil echinoids of Taiwan, II. Acta Geol. Taiwan., 1, 93-109.

Lee, H., J.-P. Lin, H.-C. Li, L.-Y. Chang, K.-S. Lee, S.-J. Lee, W.-J. Chen, A. Sankar, and S.-C. Kang, 2019: Young colonization history of a widespread sand dollar (Echinodermata; Clypeasteroida) in western Taiwan. Quat. Int., 528, 120-129, doi: 10.1016/j. quaint.2018.12.003. [Link]

Lin, C. C. and J. T. Chou, 1978: Geology of Taiwan, MaoChang Books Co. Ltd., Taipei, Taiwan, 450 pp. (in Chinese)

Lin, Y. J., 2021: Ontogenetic Patterns and Stereomic Microstructures in Clypeasteroida: A Case Study of Pleistocene Sand Dollars from Western Taiwan. Mater Thesis, National Taiwan University, Taipei, Taiwan, $91 \mathrm{pp}$.

Mooi, R., 1989: Living and Fossil Genera of the Clypeasteroida (Echinoidea: Echinodermata): An Illustrated Key and Annotated Checklist, Smithsonian Contributions to Zoology, Number 488, 51 pp, doi: 10.5479/ si.00810282.488. [Link]

Morishita, A., 1967: On the measurements of Scaphechinus mirabilis (preliminary report). Contributions to Celebrate Prof. Ichiro Hayasaka's 76th Birthday, 109-116.

Nisiyama, S., 1966: The Echinoid Fauna from Japan and Adjacent Regions: Part 1, Palaeontological Society of Japan Special Papers, Number 11, 277 pp.

Nisiyama, S., 1968: The Echinoid Fauna from Japan and Adjacent Regions: Part 2, Palaeontological Society of Japan Special Papers, Number 13, 491 pp.

Pearse, J. S. and V. B. Pearse, 1975: Growth Zones in the Echinoid Skeleton. Am. Zool., 15, 731-751, doi: 10.1093/icb/15.3.731. [Link]

Seilacher, A., 1979: Constructional morphology of sand dollars. Paleobiology, 5, 191-221, doi: 10.1017/ S0094837300006527. [Link]

Smith, A. B., 1980: Stereom Microstructure of the Echinoid Test, Special Papers in Palaeontology, Vol. 25, Palaeontological Association, $81 \mathrm{pp}$.

Smith, A. B., 1984: Echinoid Palaeobiology, Special Topics in Palaeontology, Vol. 1, George Allen and Unwin, London, $190 \mathrm{pp}$.

Smith, A. B., 1989: Biomineralization in Echinoderms. In: Carter, J. G. (Ed.), Skeletal Biomineralization: Patterns, Processes and Evolutionary Trends, Short Courses in Geology, Volume 5, American Geophysical Union, 117-147, doi: 10.1029/SC005p0117. [Link]

Smith, A. B., 1991: Echinodermata Plates 170-175. In: Carter, J. G. (Ed.), Skeletal Biomineralization: Patterns, Processes and Evolutionary Trends, Volume II, Atlas and Index, Van Nostrand Reinhold, New York, 69-71.

Towe, K. M., 1967: Echinoderm calcite: Single crystal or 
polycrystalline aggregate. Science, 157, 1048-1050, doi: 10.1126/science.157.3792.1048. [Link]

Wang, C.-C., 1982a: Study on fossil clypeasteroid echinoids of Taiwan. Master Thesis, Geological Department, National Taiwan University, Taipei, Taiwan, 173 pp.

Wang, C.-C., 1982b: On the fossil laganid echinoids from Taiwan, with a discussion of the "genus" Peronellites Hayasaka and Morishita. Science Reports of the National Taiwan University ACTA Geologica Taiwanica, 21, 140-156.

Wang, C.-C., 1984: New classification of clypeasteroid echinoids. Proc. Geol. Soc. China, 27, 119-152.

Wang, C.-C., 1986: Fossil astriclypeid echinoids from Taiwan. Proc. Geol. Soc. China, 29, 149-183.
Wang, C.-C., C.-F. Lin, and L.-C. Lee, 1984: Measurements on Late Pleistocene sand dollar Scaphechinus mirabilis from northern Taiwan. Annual Report of Central Geological Survey, 72, 49-56. (in Chinese)

Weber, J. N., 1969: The incorporation of magnesium into the skeletal calcites of echinoderms. Am. J. Sci., 267, 537-566, doi: 10.2475/ajs.267.5.537. [Link]

Yoshiwara, S., 1901: Geologic structure of the Riukiu Loochoo curve, and its relation to the northern part of Formosa. The Journal of the College of Science, Imperial University of Tokyo, Japan, 16, 1-67.

Yoshiwara, S., 1903: On the fossil echinoids of Japan. The Journal of the College of Science, Imperial University of Tokyo, Japan, 17, 1-27.

\section{APPENDIX}

Table A1. List of thin sections in Lin (2021).

\begin{tabular}{|c|c|c|c|c|c|c|c|}
\hline NTUG No. & Specimen No. & Thin section no. & Collection & NTUG No. & Specimen No. & Thin section no. & Collection \\
\hline NTUG300-FU01001 & NTU1 & NTU1 & R300 & NTUG300-FU01030 & NTU47 & NTU47 & R300 \\
\hline NTUG300-FU01002 & NTU2 & NTU2 & R300 & NTUG300-FU01031 & NTU48 & NTU48 & R300 \\
\hline NTUG300-FU01003 & NTU3 & NTU3 & R300 & NTUG300-FU01032 & NTU49 & NTU49 & R300 \\
\hline NTUG300-FU01004 & NTU4 & NTU4 & R300 & NTUG300-FU01033 & NTU50 & NTU50 & R300 \\
\hline NTUG300-FU01005 & NTU5 & NTU5 & R300 & NTUG300-FU01034 & P1 & $\mathrm{P} 1$ & R111 \\
\hline NTUG300-FU01006 & NTU6 & NTU6 & R300 & NTUG300-FU01035 & $\mathrm{P} 2$ & $\mathrm{P} 2$ & R111 \\
\hline NTUG300-FU01007 & NTU7 & NTU7 & R300 & NTUG300-FU01036 & P3 & P3 & R111 \\
\hline NTUG300-FU01008 & NTU8 & NTU8 & R300 & NTUG300-FU01037 & P4 & P4 & R111 \\
\hline NTUG300-FU01009 & NTU9 & NTU9 & R300 & NTUG300-FU01038 & P5 & P5 & R111 \\
\hline NTUG300-FU01010 & NTU10 & NTU10 & R300 & NTUG300-FU01039 & P6 & P6 & R111 \\
\hline NTUG300-FU01011 & NTU11 & NTU11 & R300 & NTUG300-FU01040 & P7 & P7 & R111 \\
\hline NTUG300-FU01012 & NTU12 & NTU12 & R300 & NTUG300-FU01041 & P8 & P8 & R111 \\
\hline NTUG300-FU01013 & NTU13 & NTU13 & R300 & NTUG300-FU01042 & P9 & P9 & R111 \\
\hline NTUG300-FU01014 & NTU14 & NTU14 & R300 & NTUG300-FU01043 & $\mathrm{P} 10$ & $\mathrm{P} 10$ & R111 \\
\hline NTUG300-FU01015 & NTU15 & NTU15 & R300 & NTUG300-FU01044 & P11 & P11 & R111 \\
\hline NTUG300-FU01016 & NTU16 & NTU16 & R300 & NTUG300-FU01045 & $\mathrm{P} 12$ & $\mathrm{P} 12$ & R111 \\
\hline NTUG300-FU01017 & NTU17 & NTU17 & R300 & NTUG300-FU01046 & $\mathrm{P} 13$ & $\mathrm{P} 13$ & R111 \\
\hline NTUG300-FU01018 & NTU18 & NTU18 & R300 & NTUG300-FU01047 & P14 & P14 & R111 \\
\hline NTUG300-FU01019 & NTU19 & NTU19 & R300 & NTUG300-FU01048 & P15 & P15 & R111 \\
\hline NTUG300-FU01020 & NTU20 & NTU20 & R300 & NTUG300-FU01049 & P16 & P16 & R111 \\
\hline NTUG300-FU01021 & NTU21 & NTU21 & R300 & NTUG300-FU01050 & P17 & P17 & R111 \\
\hline NTUG300-FU01022 & NTU22 & NTU22 & R300 & NTUG300-FU01051 & $\mathrm{P} 18$ & P18-1 & R111 \\
\hline NTUG300-FU01023 & NTU23 & NTU23 & R300 & NTUG300-FU01052 & P18 & P18-2 & R111 \\
\hline NTUG300-FU01024 & NTU24 & NTU24 & R300 & NTUG300-FU01053 & P19 & P19 & R111 \\
\hline NTUG300-FU01025 & NTU25 & NTU25 & R300 & NTUG300-FU01054 & $\mathrm{P} 20$ & $\mathrm{P} 20$ & R111 \\
\hline NTUG300-FU01026 & NTU42 & NTU42 & R300 & NTUG300-FU01055 & $\mathrm{P} 21$ & $\mathrm{P} 21$ & R111 \\
\hline NTUG300-FU01027 & NTU43 & NTU43 & R300 & NTUG300-FU01056 & $\mathrm{P} 22$ & $\mathrm{P} 22$ & R111 \\
\hline NTUG300-FU01028 & NTU45 & NTU45 & R300 & NTUG300-FU01057 & $\mathrm{P} 23$ & $\mathrm{P} 23$ & R111 \\
\hline NTUG300-FU01029 & NTU46 & NTU46 & $\mathrm{R} 300$ & NTUG300-FU01058 & $\mathrm{P} 24$ & $\mathrm{P} 24$ & R111 \\
\hline
\end{tabular}

Note: * modern S. mirabilis, indicates a modern specimen from Japan. 
Table A1. (Continued)

\begin{tabular}{|c|c|c|c|c|c|c|c|}
\hline NTUG No. & Specimen No. & Thin section no. & Collection & NTUG No. & Specimen No. & Thin section no. & Collection \\
\hline NTUG300-FU01059 & $\mathrm{P} 25$ & P25 & R111 & NTUG300-FU01073 & $\mathrm{a} 4$ & a4-2 & R111 \\
\hline NTUG300-FU01060 & P26 & P26 & R111 & NTUG300-FU01074 & $\mathrm{a} 4$ & a4-3 & R111 \\
\hline NTUG300-FU01061 & $\mathrm{P} 27$ & $\mathrm{P} 27$ & R111 & NTUG300-FU01075 & a5 & a5 & R111 \\
\hline NTUG300-FU01062 & $\mathrm{P} 28$ & P28 & R111 & NTUG300-FU01076 & a6 & a6 & R111 \\
\hline NTUG300-FU01063 & P29 & P29 & R111 & NTUG300-FU01077 & a6 & a6-2 & R111 \\
\hline NTUG300-FU01064 & $\mathrm{P} 30$ & $\mathrm{P} 30$ & R111 & NTUG300-FU01078 & a6 & a6-3 & R111 \\
\hline NTUG300-FU01065 & $\mathrm{P} 31$ & $\mathrm{P} 31$ & R111 & NTUG300-FU01079 & a7 & a7 & R111 \\
\hline NTUG300-FU01066 & P32 & P32 & R111 & NTUG300-FU01080 & a8 & a8-1 & R111 \\
\hline NTUG300-FU01067 & $\mathrm{T} 1$ & $\mathrm{~T} 1$ & R111 & NTUG300-FU01081 & a8 & a8-2 & R111 \\
\hline NTUG300-FU01068 & $\mathrm{T} 2$ & $\mathrm{~T} 2$ & R111 & NTUG300-FU01082 & a8 & a8-3 & R111 \\
\hline NTUG300-FU01069 & $\mathrm{T} 3$ & $\mathrm{~T} 3$ & R111 & NTUG300-FU01083 & a9 & a9-1 & R111 \\
\hline NTUG300-FU01070 & a2 & a2-1 & R111 & NTUG300-FU01084 & a9 & a9-2 & R111 \\
\hline NTUG300-FU01071 & $\mathrm{a} 2$ & a2-2 & R111 & NTUG300-FU01085 & a13 & a13 & R111 \\
\hline NTUG300-FU01072 & a4 & $\mathrm{a} 4-1$ & R111 & NTUG300-FU01086 & SM016* & SM016* & R111 \\
\hline
\end{tabular}

